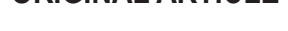

\section{Influence of Surcharge Load on the Adjacent Pile Foundation in Coastal Floodplain}

\author{
Hao Zhang, Kai Sun \\ School of Civil Engineering, Zhengzhou University, Zhengzhou, 450001
}

Abstract: In this paper, in order to investigate the behavior of existing piles caused by the horizontal and compression deformation of soft substratum due to backfill surcharge on coastal floodplain, three-dimensional finite element models of piles adjacent to surcharge load were established. The deformation and migration law of soft soil was analyzed. The behavior of single pile and double row pile adjacent to surcharge load were studied, in which the influence of surcharge load location, surcharge pressure, pile stiffness, and pile top constraint conditions were considered. The results show that as the position of surcharge load is closer and the surcharge pressure increases, the response (e.g. deformation and bending moment) is more obvious. With the increase of pile stiffness, the range of passive load is increased. The deformation behavior of pile body under different constraints of pile cap is significantly different. The effect of secondary bending moment caused by pile axial force is obvious and cannot be ignored. If there is a thick soft substratum, it is beneficial to improve the behavior of adjacent piles by using cement mixing pile reinforcement.

Keywords: Soft Soil Foundation; Surcharge Load; Passive Pile; Numerical Analysis

\section{Introduction}

In soft soil areas, ground piling often causes lateral displacement of soft foundation soil, causing lateral displacement of adjacent pile foundation and obvious change of bearing capacity of pile foundation. Vertical compressive pile originally controlled by compressive bearing and settlement may be transformed into horizontal bending resistant pile controlled by horizontal additional passive load. According to the classification standard of pile by de beer and 1, this pile is a typical passive pile that bears both the active load of superstructure and the additional passive load caused by lateral displacement of surrounding soil. The engineering behavior of passive pile not only involves the relatively complex interaction between pile and soil in three-dimensional space, but also needs to consider the coupling effect of active and passive loads. If it is not properly evaluated, it will easily lead to serious engineering accidents. For example, a viaduct of a highway junction in Zhangjiagang caused an accident of pier column deviation across the line due to the foundation load of the interchange ramp road ${ }^{[2]}$; The partial pile foundation of a super-large high-speed railway bridge ( 9 ,\# and $10, \#$ ) caused by a large area of one-sided pile load resulted in a serious deviation accident ${ }^{[3]}$ etc. Especially in recent years, with the rapid development of industrialization and urbanization in coastal areas, reclamation of land from the sea and reclamation of coastal land by roads have become important ways to relieve the shortage of land resources. More and more land reclamation, dumping and reclamation projects have been carried out. However, the current design specifications in China have not yet fully considered the adverse effects of lateral displacement of soil around piles. Therefore, the impact of backfilling and stacking on nearby buildings, especially the impact of stacking on the properties of adjacent piles, has become a hot topic for current research.

Due to the complex and changeable soil quality of soft soil foundation and the different forms of superstructure, it is difficult to draw reliable conclusions by model tests. Finite element numerical model analysis has become an ideal

Copyright (C) 2020 Hao Zhang et al.

doi:10.18282/ice.v3i1.312

This is an open-access article distributed under the terms of the Creative Commons Attribution Non-Commercial License (http://creativecommons. org/licenses/by-nc/4.0/), which permits unrestricted non-commercial use, distribution, and reproduction in any medium, provided the original work is properly cited. 
method to study this problem. Randolph $(1981)^{[4]}$, Spring Man (1984) ${ }^{[5]}$ established a two-dimensional numerical model and analyzed the performance of passive piles by plane strain method;' Carter (1982) ${ }^{[6]}$ used axisymmetric method to carry out finite element analysis on passive piles. Wei Rulong (1992) $)^{[7]}$ and Wang Nianxiang (1998) ${ }^{[8]}$, etc. have studied the interaction between pile and soil in high-pile wharf by using plane finite element method. Chen Fuquan and Min Yang, (2005) ${ }^{[9]}$ analyzed the influence of pile loading on nearby single and double row piles under different working conditions by using two-dimensional numerical model; Kelesogu (2011) ${ }^{[10]}$ and others have established a threedimensional numerical model to analyze the passive loading response of abutment pile foundation during subgrade filling. Zheng Jianlong, (2013 $)^{[11]}$ and others also analyzed the influence of subgrade filling on nearby piles by using a three-dimensional numerical model, but did not involve the influence of pile top constraint in actual engineering.

In this paper, combined with a coastal floodplain backfilling and land reclamation project in Shenzhen, the heaped load is established by using the method of three-dimensional finite element numerical analysis. The analysis model of deformation and stress characteristics of adjacent pile foundation under the action reveals the migration rule of soft soil under the action of pile load, and systematically

This paper analyzes the effect of landfill loading on the pile foundation of the adjacent expressway viaduct in the overbank mud storage area in the project, so as to reasonably evaluate the loading. It provides basis for the influence of adjacent pile foundation.

\section{Engineering background and model construction}

\subsection{Project overview}

A coastal floodplain backfilling and land-building project in Shenzhen is located in the northwest coastal area of Bao'an Airport. The original landform of the site is the coastal shoal of the Pearl River Estuary-intertidal zone, belonging to the muddy beach area, and its east side is the alluvial plain landform. The terrain of the site is relatively complex. The original site is mainly composed of fish ponds and rivers, and the surface water body is developed. Figure 1 is a schematic diagram of the plane position of the project. the site area consists of four spoil backfilling areas, a, b, c and $\mathrm{d}$, and the riverside expressway passes through the east side of the site area. Among them, areas a, c and $\mathrm{d}$ are the backfilling area of Phase I located on the west side of the viaduct along the Yangtze River. The boundary of the area is about $200 \mathrm{~m} \sim 230 \mathrm{~m}$ away from the viaduct. The maximum width of backfilling area can reach $200 \mathrm{~m}$ B and Zone are the second-stage backfilling areas, with the second-stage Shajing Interchange of the Yangtze River Expressway in the area.

It can be seen that the backfilling area in the land reclamation area is large in area and widely distributed, and its impact on the stability of the viaduct along the adjacent riverside expressway cannot be ignored.

According to relevant engineering data, the backfill soil formed on the land area is generally dredged and filled with sand and gravel and backfilled for construction. The basic requirements of soil quality for building muck or spoil are: natural water content is not more than $50 \%$, organic matter content is not more than $10 \%$, and if the stone is contained, the particle size of the stone should be less than $30 \mathrm{~cm}$, (the particle size is between $2 \mathrm{~cm} \sim 30 \mathrm{~cm}$ and the content should not exceed 10\%). The physical and mechanical indexes of the main strata and their rock and soil layers in the site are shown in Table 1. Silt layers ( (2) 1and (2) 2, thickness $12 \mathrm{~m} \sim 18 \mathrm{~m}$ ) and organic clay layers ( (4), thickness $18 \mathrm{~m} 22$ $\mathrm{m})$ with low consolidation, low strength and poor self-stabilization capability are distributed in the site. Consolidation settlement and lateral extrusion are easy to occur under the working conditions of engineering construction and additional load of fill. Therefore, the adverse effects of soft soil on the adjacent bridge foundation should be considered in the backfilling construction of land formation. 


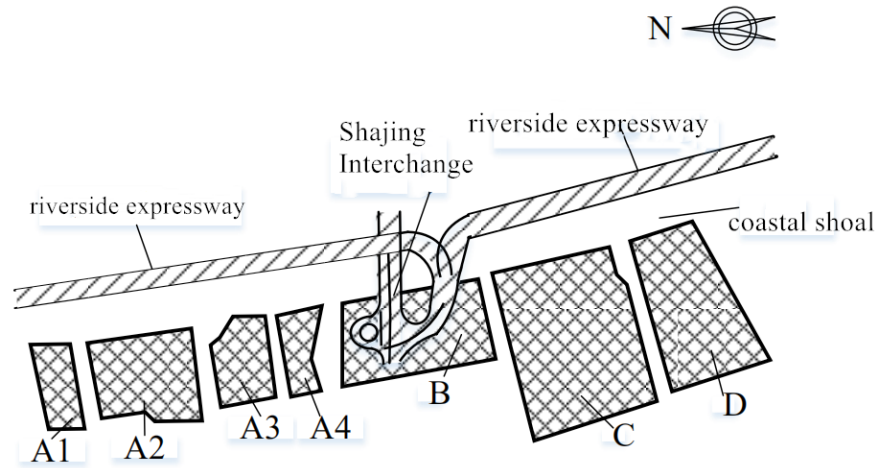

Fig.1 Schematic diagram of the project

Tab. 1 Physical and mechanical indexes of each rock and soil layer

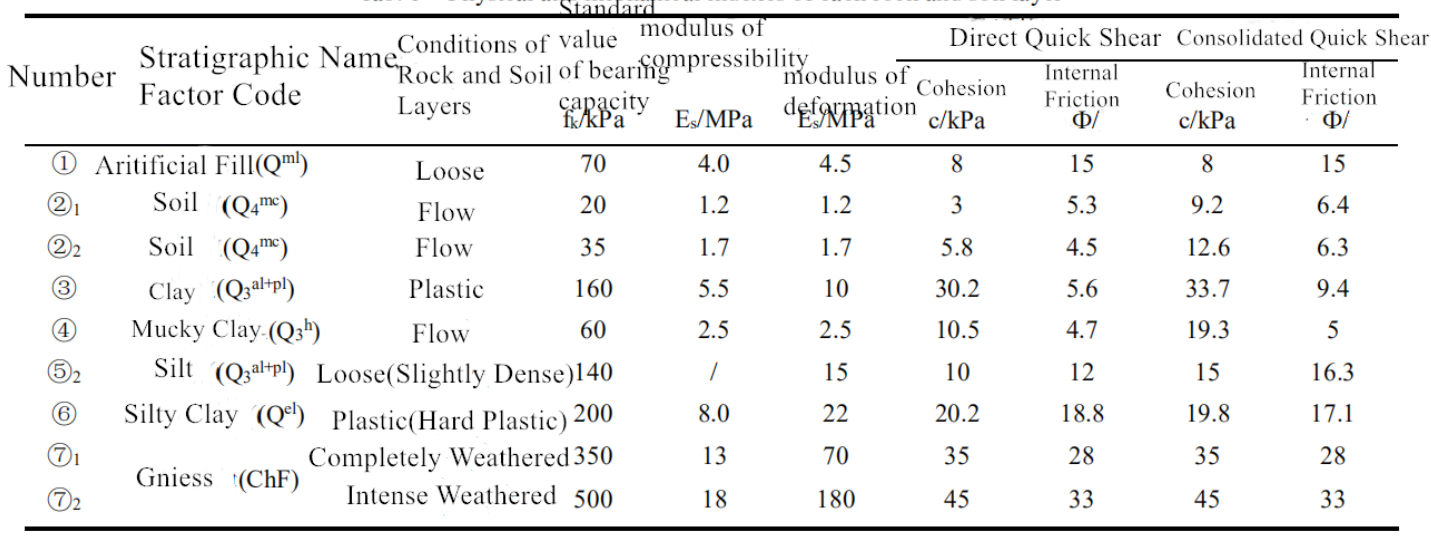

\subsection{Finite element model}

In order to systematically analyze the effect of backfill pile loading on adjacent pile foundations, and in combination with site conditions, pile-free pile loading model, adjacent pile-loading single pile model and adjacent pile-loading bridge pile row model are respectively established, as shown in Figure 2. The total length of the model is $150 \mathrm{~m}$ and the width is $60 \mathrm{~m}$. Considering symmetry, the stacking length is taken as $100 \mathrm{~m}$, with slope width $6 \mathrm{~m}$, slope $2 / 3$. In order to facilitate analysis, the strata in the site are simplified into silt layer ( $15 \mathrm{~m}$ thick), clay layer (20 $\mathrm{m}$ thick) and hard soil layer/rock layer according to soil layer characteristics. According to the actual engineering design data, the parameters of pile body shall be taken as pile length, pile diameter, pile diameter, pile rigidity and pile body rigidity of $30 \mathrm{GPa}$. Among them, the constraint effect of bridge bearing platform and upper column is considered in the pile arrangement model of adjacent piled bridge. The pile top is provided with length $10 \mathrm{~m}$ column and bearing platform, front and rear pile arrangement spacing $6 \mathrm{~m}$ front pile distance $\mathrm{d}=10 \mathrm{~m}$. The column bearing platform and column are fixedly linked, as shown in Figure 2(c). When establishing the model, the pile and pile are linear elastic bodies, the soil around the pile and the pile bottom are elastic-plastic materials, and obey the Mohr-Coulomb yield criterion. The specific parameters are shown in Table 2.

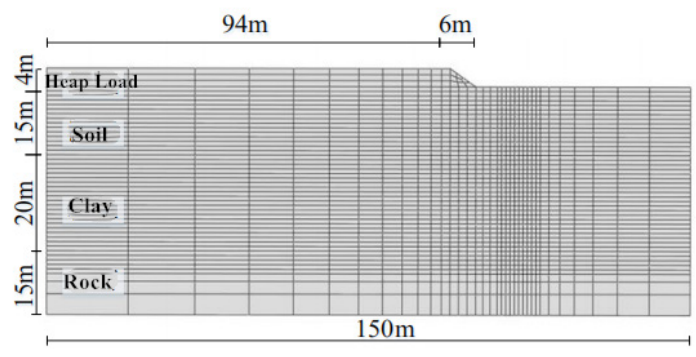

(a) Pile-up action model without piles 


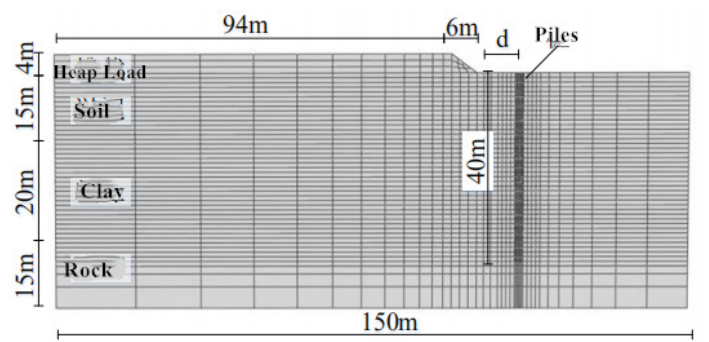

(b) Adjacent stowage single pile model

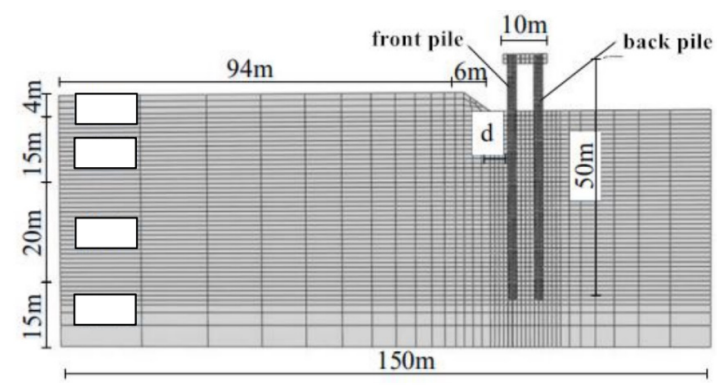

(c) Pile row model of adjacent stowed bridge

Tab.2 Calculation parameters

\begin{tabular}{|c|c|c|c|c|c|c|}
\hline \multicolumn{2}{|c|}{ soil layerdensityg/ $/ \mathrm{cm}^{3}$} & \multicolumn{2}{|c|}{$\begin{array}{cc}\text { elastic modulus } & \begin{array}{c}\text { Poisson's } \\
\text { ratio }\end{array} \\
\end{array}$} & \multirow{2}{*}{$\begin{array}{l}\begin{array}{l}\text { internal } \\
\text { friction } /^{\circ} \\
\text { angle }\end{array} \\
-\end{array}$} & \multirow{2}{*}{$\begin{array}{c}\text { cohensionc/kPa } \\
-\end{array}$} & \multirow{2}{*}{$\begin{array}{l}\begin{array}{l}\text { expansion/o } \\
\text { angle }\end{array} \\
-\end{array}$} \\
\hline heap load & 1.5 & 40 & 0.3 & & & \\
\hline soil & 1.5 & 15 & 0.4 & 6 & 15 & 0.1 \\
\hline clay & 1.8 & 80 & 0.3 & 10 & 30 & 0.1 \\
\hline rock & 2.5 & 200 & 0.25 & 33 & 45 & 0.1 \\
\hline pile & 2.5 & 30000 & 0.2 & - & - & - \\
\hline
\end{tabular}

\section{Analysis of effect of heap load}

As shown in Figure 3, the displacement nephogram of the basement stratum under the designed backfilling and stacking action ( $h=4 \mathrm{~m}, \mathrm{p}=90 \mathrm{kPa}$ ). It can be seen that the basement stratum has obvious settlement deformation and lateral displacement under the action of backfilling and stacking.

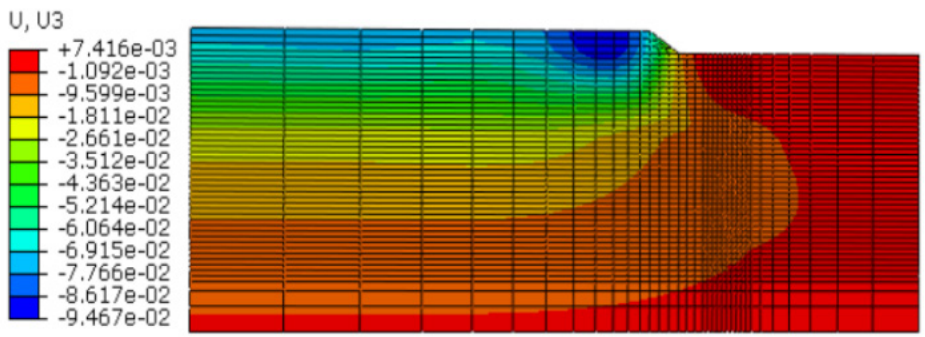

(a) Sedimentation

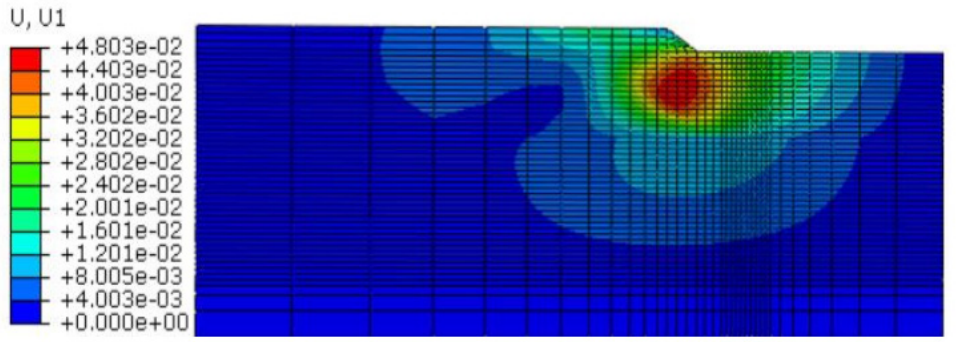

(b) Lateral Displacement

Fig.3 Deformation of substratum

Take the toe of the heaped slope as the origin of coordinates, and extract the formation settlement deformation at 
different depths, as shown in Figure 4. Under the action of backfilling and stacking, the settlement of the lower stratum is obvious, but the settlement deformation shows a gradually decreasing trend with the increase of soil depth. However, the uplift of the soil in the local area adjacent to the heaped load indicates that the lateral extrusion of the base soil occurs with the occurrence of settlement deformation.

Figure 5 are soil lateral displacement curves at different distances from the heaped load, while keeping the other parameters unchanged, and the total length of the model is established.

250m Pile-free Stacking Model. It can be seen that the lateral displacement of the soil decreases with the increase of the distance from the pile load. When the distance of the pile load is greater than $120 \mathrm{~m}$, the lateral movement of the soil tends to zero. In this project, the distance between the A, area, C, area, D and area from the viaduct of Yanjiang Expressway is more than $200 \mathrm{~m}$.It can be considered that the backfilling and stacking of the viaduct has basically no influence on the pile foundation of the nearby bridge. However, there is Shajing Interchange on the viaduct of Yanjiang Expressway in the B and Field. The influence of backfilling and stacking on the pile foundation of the interchange bridge cannot be ignored in the later construction.

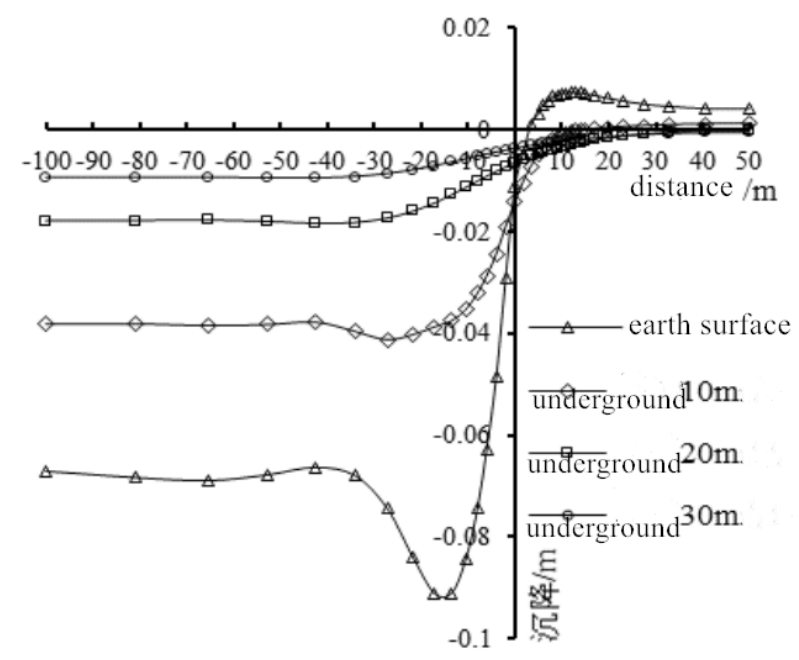

Fig.4 Settlement curves at different depths

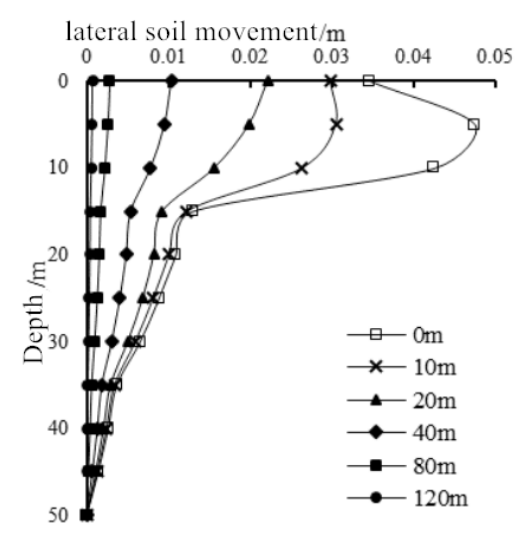

Fig.5 Lateral deformation at different distance from surcharge load

\section{Single pile impact response}

In order to further reveal the influence of pile loading on the working behavior of adjacent pile foundations, the finite element models of single pile based on adjacent pile loading are compared respectively.

\subsection{Heap position}

Considering the influence of pile position on pile body behavior, the working conditions of distance from pile $\mathrm{d}=$ $0 \mathrm{~m}, 10 \mathrm{~m}, 20 \mathrm{~m}$, and $40 \mathrm{~m}$ are compared and analyzed, and the pile side movement change curve and bending moment 
change curve at different pile positions are obtained, as shown in Figure 6. Figure 6(a) is the relationship curves of pile side movement with pile distance from single pile. The lateral displacement of the pile gradually decreases with the increase of the distance from the pile load. When the pile is next to the pile load $(\mathrm{d}=0 \mathrm{~m})$, the maximum lateral displacement of the pile body is $26.4 \mathrm{~mm}$, which is increased by $48.3 \%, 1.3 \%, 7.5 \%$, respectively compared with the maximum lateral displacements of the distances of $10 \mathrm{~m}, 20 \mathrm{~m}, 40 \mathrm{~m}$, indicating that the pile load distance has a more obvious influence on the deformation behavior of the pile body.

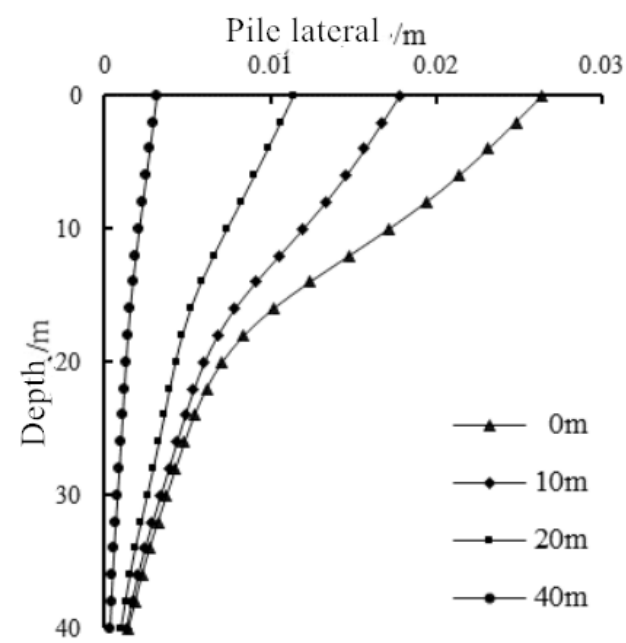

(a) Lateral

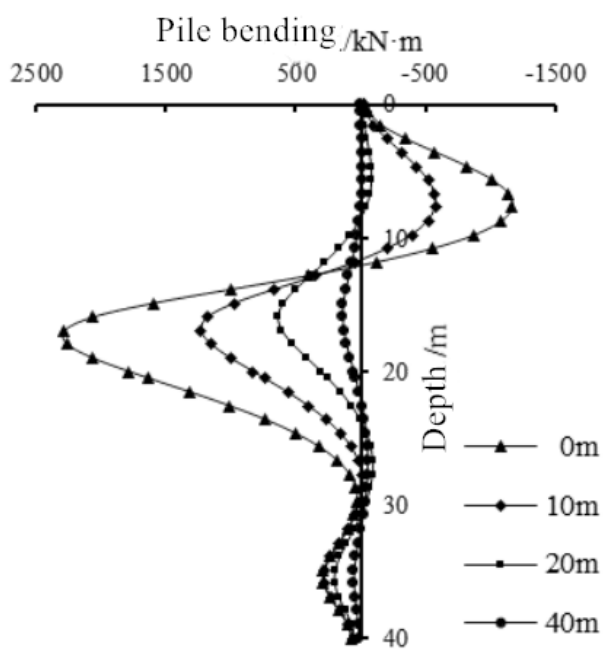

(b) Bending

Fig.6 Lateral deformation and bending moment of pile at different distance from surcharge load

Figure 6(b) is the curves of pile bending moment versus pile distance. The maximum bending moment of the pile body is located at the boundary between the silt layer and the clay layer. The maximum bending moment of the pile body is $2264 \mathrm{kN} \cdot \mathrm{m}$, which is further increased by $83.6 \%, 2.7 \%$, times and 16 times than the maximum bending moments of $10 \mathrm{~m}, 20 \mathrm{~m}, 40 \mathrm{~m}$, respectively. The position of the maximum bending moment gradually moves down with the decrease of the stacking distance. The pile force changes obviously and the range affected by the passive load increases.

\subsection{Pile stiffness}

When the stacking distance is $10 \mathrm{~m}$, keep other parameters unchanged, change the stiffness of the pile body, and analyze the lateral displacement and bending moment variation of the pile body under the stacking load when the pile body stiffness is $1 \mathrm{GPa}, 5 \mathrm{GPa}, 10 \mathrm{GPa}, 20 \mathrm{GPa}$ and $30 \mathrm{GPa}$.

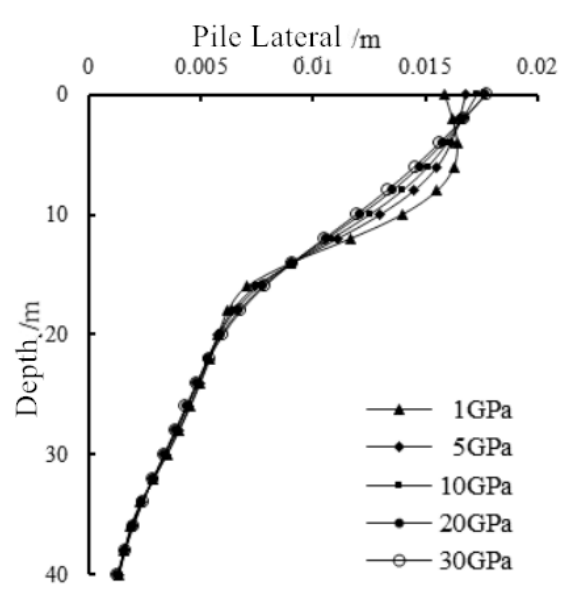

(a) Lateral

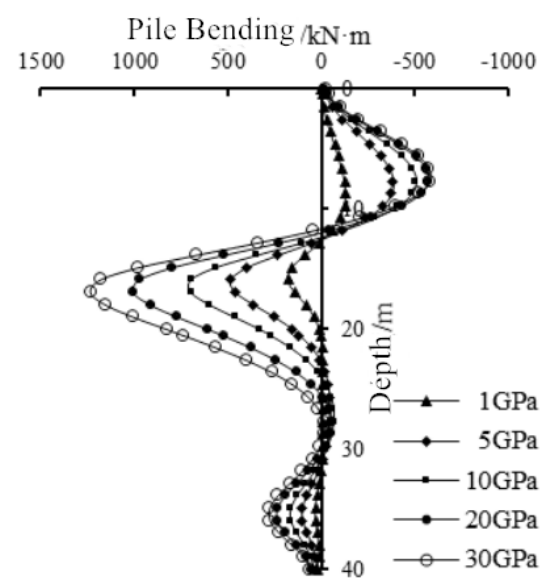

(b) Bending

Fig.7 Lateral deformation and bending moment of pile with different stiffness

Figure 7(a) is a curve showing the relationship between the lateral displacement of the pile and the stiffness of the 
pile body. it can be seen that when the stiffness of the pile body is greater than 10GPa. The lateral displacement curve gradually decreases from top to bottom, and the maximum displacement of pile body occurs at the top of pile. When the stiffness of the pile body is less than when $10 \mathrm{GPa}$ is used, the lateral displacement curve shows parabolic distribution, and the maximum displacement of pile body occurs in the middle of silt layer.

Considering the influence of pile stiffness on the bending moment of pile body, the maximum bending moment of pile body is $1233 \mathrm{kN} \cdot \mathrm{m}$ when the pile body stiffness is $30 \mathrm{GPa}$, which is $22.9 \%, 77.4 \%, 1.7 \%$, and 8 times higher than the pile body stiffness of $20 \mathrm{GPa}, 10 \mathrm{GPa}, 5 \mathrm{GPa}$, and $1 \mathrm{GPa}$ respectively, indicating that the bending moment of pile body increases with the increase of pile body stiffness. The maximum bending moment value is basically located at the boundary between silt layer and clay layer, and the position of the maximum bending moment value of pile body gradually moves down with the increase of pile body rigidity, and the range affected by passive load increases, as shown in Figure 7(b).

\subsection{Heap load level}

Considering the influence of the pile load level, the load levels are analyzed as $60 \mathrm{kPa}, 90 \mathrm{kPa}, 120 \mathrm{kPa}, 150 \mathrm{kPa}$ and $180 \mathrm{kPa}$ respectively. The lateral displacement and bending moment changes of pile body under the pile load are analyzed.

Figure 8(a) is the relationship curves of pile side movement with pile load level. The lateral displacement of the pile mainly occurs in the silt layer, and the maximum lateral displacement is at the top of the pile. The larger the pile load level is, the larger the pile side displacement is. when the load level is $180 \mathrm{kPa}$, the maximum lateral displacement deformation of the pile body is as high as $9.7 \mathrm{~cm}$, which is increased by $34.7 \%, 94 \%, 2 \%$, times and 4.7 times respectively compared with the maximum lateral displacement of the load levels of $150 \mathrm{kPa}, 120 \mathrm{kPa}, 90 \mathrm{kPa}$ and 60 $\mathrm{kPa}$.

Figure 8 are the curves of pile bending moment versus pile load level. With the increase of the pile load level, the bending moment of the pile body shows an increasing trend. When the load level is $180 \mathrm{kPa}$, the maximum bending moment of the pile body is $8239 \mathrm{kN} \cdot \mathrm{m}$, which is $37.9 \%, 1,2.5$, times and 6 times higher than the maximum bending moments of the load levels of $150 \mathrm{kPa}, 120 \mathrm{kPa}, 90 \mathrm{kPa}$ and $60 \mathrm{kPa}$ respectively.

The maximum bending moment of pile body is located at the boundary between silt layer and clay layer, and the position of reverse bending point gradually moves up with the increase of load. The larger the pile load is, the larger the pile affected by pile load.

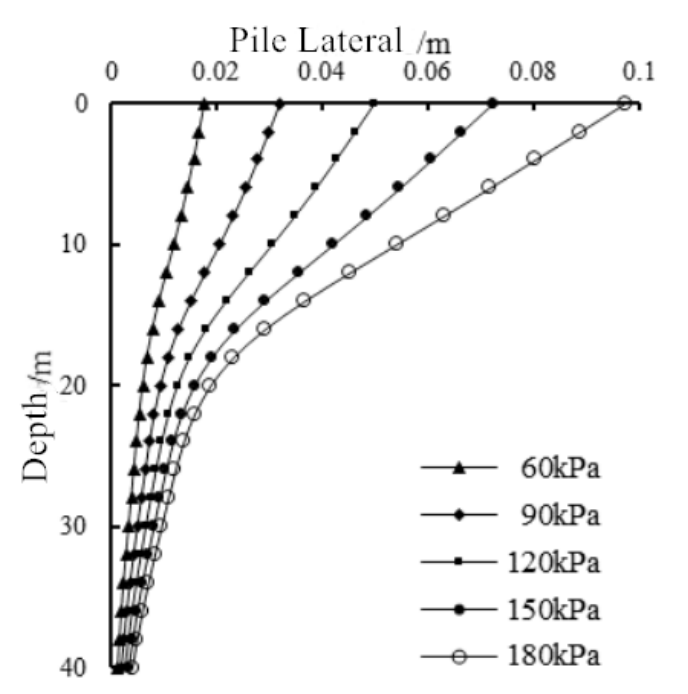

(a)Lateral

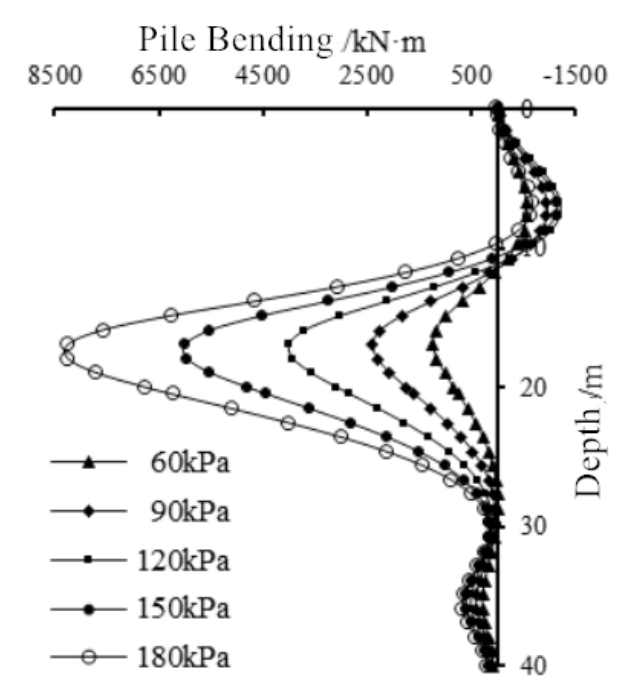

(b) Bending

Fig.8 Lateral deformation and bending moment of pile under different surcharge pressure 


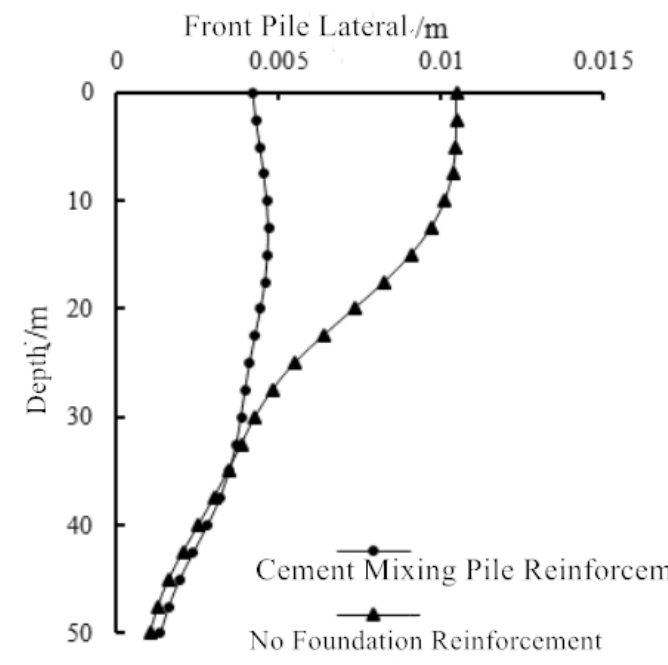

(a) Front pile

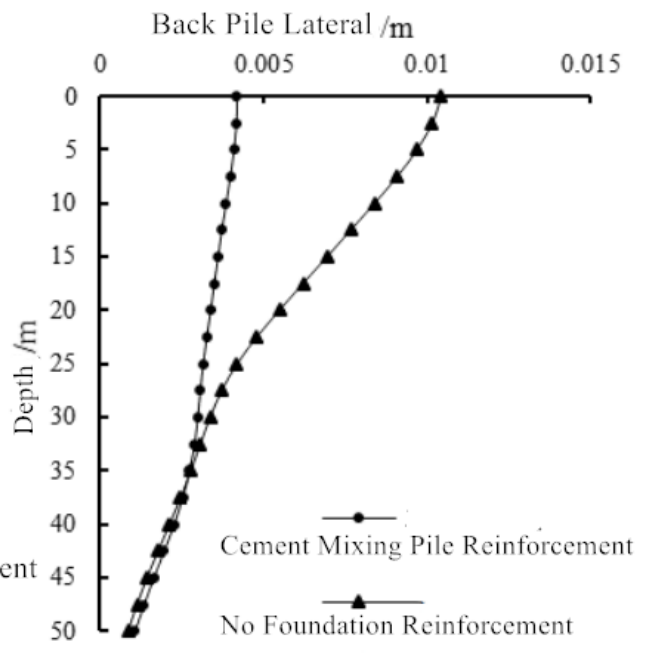

(b) Back Pile

Fig.12 Influence of ground reinforcement on pile lateral deformation

\section{Conclusion}

In this paper, based on a coastal floodplain backfilling project in Shenzhen, three-dimensional numerical calculation system is used to analyze the backfilling on soft soil foundation

The effect of pile load on adjacent pile foundation is mainly as follows:

(1). Pile position and load level have significant effect. the closer the pile position is, the higher the load level is, the deformation and stress of pile body will be. The more obvious the response is, the sufficient distance ( $>120 \mathrm{~m})$ should be reserved from the existing pile foundation in the backfill engineering design to reduce the additional load on the pile and the influence of load effect.

(2). The restraint effect of the superstructure adjacent to the pile foundation under the action of pile load is significant, and the bridge pile foundation should be based on different column top. The design checking calculation is carried out under the constraint of bearing, and the "secondary bending moment" effect caused by axial force of pile body is obvious and cannot be ignored.

(3). Foundation reinforcement (cement mixing pile) has a good improvement effect on the soft soil of the foundation, which can obviously reduce the stacking load.

\section{References}

1. DEBEER E E. The effects of horizontal loads on piles,due to surcharge or seismic effects[C]/Proc 9th ICSMFE. Tokyo,1977:547-558.

2. Zhang Hao, Shi Minglei, Guo Yuancheng, et al. Displacement characteristics and stress analysis of bridge foundation pile-column under side load [J]. Geotechnical Mechanics, 2017,38(09):2683-2692.

3. Liang Dong, Niu Bin, Gu Mu, et al. Numerical analysis of the influence of large-scale unilateral loading on piers and abutments of high-speed railway bridges [J]. Railway Architecture, 2015(01):39-42.

4. RANDOLPH M F. The Response of Flexible Plies to Lateral Loading [J]. Geotechnique,1981,31(2):247-259.

5. SPRINGMAN S M. Lateral Loading on Pile due to Embankment Construction [D]. Cambring:Cambring University,1984.

6. CARTER J P. Anumerical method fo pile deformations due to nearby surface loads[C]//Proceeding of the Fourth International Conference on Numercial Methods in Geomechanics Edmonton.1982: 811-817.

7. Wei Rulong, Wang Nianxiang, Yang Shouhua. Interaction between pile wharf and bank slope [J]. Journal of Geotechnical Engineering, 1992(06):38-49.

8. Wang Nianxiang. Study on numerical simulation and simplified calculation method of interaction between wharf pile foundation and bank slope [D]. Nanjing: nanjing hydraulic research institute, 1998. 
9. Chen Fuquan, Min Yang. Numerical analysis of the behavior of adjacent pile foundations under ground loading [J]. Journal of Geotechnical Engineering, 2005(11):51-55.

10. KELESOGLU M K, SPRINGMAN S M. Analytical and 3D numerical modelling of full-height bridge abutments constructed on pile foundations through soft soils[J]. Computers and Geotechnics, 2011, 38(8):934-948.

11. Zheng Jianlong, Zhang Junhui, Li Xuefeng. Influence of Soft Foundation Bridge Head Subgrade Filling on Abutment Piles [J]. china journal of highway and transport, 2013,26(02):48-55. 